\title{
Influence of water stress prior to harvest on yield and essential oil content of pot grown lemon balm
}

\author{
Stefan Gordanić ${ }^{1}$, Dragoja Radanović ${ }^{1}$, Milan Lukić ${ }^{1}$, Snežana Mrean ${ }^{1}$, Sara Mikić ${ }^{1}$,

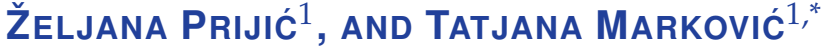 \\ ${ }^{1}$ Institute for Medicinal Plants Research "Dr. Josif Pančić", Tadeuša Koščuška 1, 11000 Belgrade, Serbia \\ *Corresponding author: tmarkovic@mocbilja.rs
}

Published: December 25, 2021

Received: November 18, 2021

Accepted: December 1, 2021

Published on-line: December 13, 2021

\begin{abstract}
Lemon balm (Melissa officinalis L.) is a perennial herbaceous plant widely used in modern and traditional medicine. The aboveground part, particularly the leaves, has many benefits; in traditional medicine, it is used for the preparation of various teas and tea blends, while in modern medicine to obtain essential oil as it is considered a precious product. Nowadays, the needs for lemon balm are mostly met by growing it in the open field. The quality of its leaves as well as the content of its essential oil mostly depend on the way the plant is grown. In stress conditions, medicinal plants use to increase the content of their secondary metabolites. Therefore, this study aimed to determine whether water deficit has an impact on the content of essential oil in lemon balm grown as a pot culture. The experiment was conceived in such a way that at the beginning of the flowering phase, cultivated plants were given different treatments. Treatment $\mathrm{A}$ represented plants that were not subjected to water stress, while in treatments $B$ and $C$, prior to harvesting the plants have been subjected to water stress for 7 and 14 days, respectively. By the end of the experiment, the morphological parameters per plant were measured and the contents of essential oil per treatment determined, all in triplicates. The obtained results indicate that water stress had a great impact on the yield of the aboveground biomass of lemon balm plants as well as on the content of essential oil in their leaves. The highest average yield of the aboveground biomass was obtained in treatment A (1204.0 g) while the highest average yield of the essential oil in treatment $C(0.59 \mathrm{~g})$. In short, an increase in water stress increased its positive effects on lemon balm grown as pot culture.
\end{abstract}

Key words: Melissa officinalis; cultivation; water deficit

http://dx.doi.org/10.5937/leksir2141054G

\section{INTRODUCTION}

Lemon balm (Melissa officinalis L.) is a perennial medicinal, aromatic, herbaceous plant species from the Lamiaceae family (Burge, 1980). This medicinal plant has been used all over the world for more than 2000 years (Abuhamdah and Chazot, 2008). Its herb is mostly used to treat mental, cardiovascular, respiratory, carcinogenic disorders, as well as to improve memory, and as an antidepressant and even antidote (Świąder et al., 2019). Also, great importance is associated with its essential oil, which has a spasmolytic, sedative, and antibacterial effect (Schultze et al., 1992).

M. officinalis is successfully grown in Asia Minor, Central and Southern Europe (Dastmalchi et al., 2008). The plant has a well-developed fibrous root that permeates the soil, well absorbing the nutrients from it. The stem is erect, hairy, 40 to $120 \mathrm{~cm}$ high, irregular in shape, while the leaves are hairy, ovate to rhomboid in shape, serrated along the rim. They usually bloom in late summer or early autumn, the flowers are white and small, while the seeds are small and elliptical (Moradkhani et al., 2010).

Lemon balm is mainly cultivated for its leaves and essential oil. Its fragrant leaves have an extensive use-value in medicine and cuisine. They contain secondary metabolites such as essential oil, polyphenols, triterpenes, fatty acids, and mineral compounds (Basar and Zaman, 2013). According to Ramakrishna and Ravishankar (2011), in order to achieve the highest productivity of secondary compounds it is necessary to grow the plant under optimal agroecological conditions. However, Pereira et al. (2014) pointed out that the production of essential oils and their composition are greatly influenced by environmental conditions, while Moradkhani et al. (2010) suggested that the content of essential oil in leaves depends on the plant developmental stage. Other studies presented significant variability in essential oil content in plants exposed to stress conditions (Farahani et al., 2009; Németh-Zámbori et al., 2016). 
Since the literature data indicate that stressful growing conditions may affect the content and composition of the essential oil, this study aimed to explore how stress induced by water deficit affects the plant yield and content of essential oil in the leaves of lemon balm grown as pot culture.

\section{MATERIALS AND METHODS}

\subsection{Seedling production in laboratory conditions}

The seeds of lemon balm (M. officinalis L.) used in this experiment originated from the MAP collection of the Institute for Medicinal Plants Research "Dr. Josif Pančič", in Pančevo, Serbia. Production of seedlings started by the end of September 2020 in the laboratory of the Institute's Department for Research and Development in Agriculture, in Belgrade, Serbia. The seedlings have been produced in Styrofoam containers with 160 cells, filled with a sowing substrate "Gramoseed Fin peat" (Gramoflor, Romania) of following characteristics provided by the manufacturer: structure $0-5 \mathrm{~mm}$, fertilizer NPK 18:10:20+Mg+me in dose of $0.8 \mathrm{~kg} / \mathrm{m}^{3}$, RADIGEN®- Jost $\mathrm{GmbH}$ (slow-release micronutrient) in dose of $100 \mathrm{~g} / \mathrm{m}^{3}$, hydrogel (wetting agent) in dose of $1 \mathrm{~kg} / \mathrm{m}^{3}$. After the sowing, the containers were kept inside a polyethylene tent (Grow Box), under the following growing conditions: the artificial lighting produced by cool fluorescent tubes with a 12-hour photoperiod; the relative humidity of 50 to $65 \%$; the air temperature was from $20^{\circ} \mathrm{C}$ to $23{ }^{\circ} \mathrm{C}$, while the substrate was kept moist and its temperature was $23 \pm 2{ }^{\circ} \mathrm{C}$. Monitoring of the air temperature and relative humidity in the Grow Box was provided by the use of HAXO-8 Data logger.

\subsection{Hardening-off process and overwintering of the pot plants in the greenhouse}

With the emergence and development of the first true leaves, by the end of October 2020, the 3 weeks long hardening-off process (adaptation) began, as recommended by Davies et al. (2017). Then the containers were taken outside the Grow box and left inside the laboratory, and they were occasionally taken outside in order to ensure adaptation of seedlings to natural light irradiance, lower air temperatures, and reduced relative air humidity. The plants were watered with tap water. At the end of the adaptation process, in mid-November 2020, the containers were transferred to a greenhouse where the plants were transplanted into plastic pots filled with $0.83 \mathrm{~L}$ peat transplanting substrate (Cultivo I SF) of following characteristics provided by the manufacturer: structure $0-6 \mathrm{~mm}$, fertilizer NPK 18:10:20+Mg+me $-1 \mathrm{~kg} / \mathrm{m}^{3}$, RADIGEN $®$ - Jost $\mathrm{GmbH}$ (slow-release micronutrient) $-50 \mathrm{~g} / \mathrm{m}^{3}$, hydrogel (wetting agent) $-1 \mathrm{~kg} / \mathrm{m}^{3}$. The pots with plants were placed on a heating mat under which was $1 \mathrm{~mm}$ thick black "agrotextil" film covering the greenhouse ground. During the winter period, the plants used to be regularly watered every third day. In the greenhouse, the air temperature ranged from 10 to 13 ${ }^{\circ} \mathrm{C}$ and relative humidity was about $65 \%$. Monitoring of the air temperature and relative humidity in the greenhouse was provided by the use of BL30 Data logger.

\subsection{Plant growth outdoors}

At the beginning of April 2021, the potted plants were taken out outdoors and placed on black "agrotextil" film covering a $3 \mathrm{~m}^{2}$ area (90 pots) and they were irrigated with tap water using a drip irrigation system with a flow rate of 1 liter per hour for each pot. Irrigation was applied every two days for $60 \mathrm{~min}$.

\subsection{Treatments and monitored parameters}

At the beginning of the flowering phase, the produced plants were taken back to the laboratory. To study how water stress affects plants' morphological traits and leaf essential oil content, the plants were separated into three groups $(\mathrm{A}, \mathrm{B}, \mathrm{C})$, with 30 pots in each group ( 30 pots stand for $\mathrm{m}^{2}$ of the surface area). Two weeks prior to harvesting, the plants from each group were submitted to the different levels of water deficit as follows: in treatment A the plants were not submitted to water deficit, i.e., they have been watered regularly for two weeks (control), in the treatment $B$ the plants have been watered regularly for 7 days and then left without water for 7 days, while in the treatment $C$ the plants have been left without water for 14 days. During the entire treatment period (two weeks) the air temperature in the laboratory was $22{ }^{\circ} \mathrm{C}$ and relative humidity $43 \%$, which has been monitored using HAXO-8 Data logger.

\subsubsection{Morphological parameters and harvest}

When the two-week treatment period was completed, the plants from each treatment $(\mathrm{A}, \mathrm{B}, \mathrm{C})$ were subjected to the following measurements of morphological parameters: plant height $(\mathrm{cm})$, number of branches, and internode length $(\mathrm{cm})$. Then, the aboveground parts of the plants were harvested and their fresh and absolute dry mass was measured and expressed as $\mathrm{g}$ / plant. Leaf and stem ratio was also determined (g/plant).

\subsubsection{Extraction of essential oil}

The air-dried leaves of lemon balm have been submitted to distillation for $2 \mathrm{~h}$ in a Clevenger type apparatus, according to the procedure I, explained in the Ph. Jug. IV (1984). In short, for determination of the content of essential oil from the plants in each treatment (A, B, C), $100 \mathrm{~g}$ of their air-dry leaves were sampled and placed in a round bottom flask filled with 400 $\mathrm{mL}$ of tap water. The extractions were done in triplicates.

\subsubsection{Statistical analysis}

All measurements in the study have been done in triplicate. The obtained data were analyzed by analysis of variance (ANOVA) using STATISTICA 7.0 software. Multiple comparisons of treatments were performed by using Duncan's test to detect significant differences between the arithmetic means $(\mathrm{P}<0.05)$.

\section{RESULTS AND DISCUSSION}

The results presented in Table 1, show that due to a lack of water, induced water stress significantly affected the yield of the aboveground plant part, including the leaf and the stem yields, the number of branches, plant height, and length of internodes, but also the content of leaf essential oil, in both treatments, compared to control. The highest yield of the aboveground part was obtained in treatment A $(40.13 \pm 5.62)$, which the same way affected the leaf and the stem yield, the number of branches, plant height, and the length of internodes $(22.5 \pm 3.15,17.63 \pm 2.12,13.67 \pm 2.19,65.5 \pm 9.17$ and $4.21 \pm$ 0.63 , respectively). The highest content of essential oil was recorded in treatment $C(0.59 \pm 0.03 \%)$ while in treatments $\mathrm{A}$ and $\mathrm{B}$, the contents were lower $(0.44 \pm 0.02$ and $0.49 \pm 0.02$, respectively).

Based on the results of this research, it can be concluded that water stress had a positive effect on leaf essential oil content but it negatively affected the yield of the aboveground plant part and the morphological characteristics. Our results are consistent with that of Bazzazi et al. (2013) which stated that the Trigonella foenum-graecum plants use to reduce growth and yield under unfavorable environmental influences. The same study confirmed that the induced water stress reduced the yield of the aboveground plant part by $43 \%$, also affecting the plants' height. Negative effects were observed on quantitative and qualitative characteristics of Coriandrum sativum 
Table 1. Essential oil yield, different plant parts dry mass yield and morphometric parameters of the lemon balm (Melissa officinalis L.) plants cultivated in pots with different water regimes as treatments

\begin{tabular}{|c|c|c|c|c|c|c|c|}
\hline \multirow[t]{2}{*}{ Treatment } & $\begin{array}{r}\text { Essential oil } \\
\text { content }^{\mathrm{a}}\end{array}$ & $\begin{array}{l}\text { Dry mass of } \\
\text { the above- } \\
\text { ground part }\end{array}$ & $\begin{array}{r}\text { Dry mass of } \\
\text { the leaf }\end{array}$ & $\begin{array}{r}\text { Dry mass of } \\
\text { the stem }\end{array}$ & $\begin{array}{r}\text { Number of } \\
\text { branches }\end{array}$ & Plant height & $\begin{array}{l}\text { Internode } \\
\text { lengths }\end{array}$ \\
\hline & {$[\%]$} & [g/plant] & [g/plant] & [g/plant] & & {$[\mathrm{cm}]$} & [cm] \\
\hline A, control treatment & $0.44 \pm 0.02 \mathrm{c}$ & $40.13 \pm 5.62 \mathrm{a}$ & $22.5 \pm 3.15 \mathrm{a}$ & $17.63 \pm 2.12 \mathrm{a}$ & $13.67 \pm 2.19 \mathrm{a}$ & $65.5 \pm 9.17 \mathrm{a}$ & $4.21 \pm 0.63 \mathrm{a}$ \\
\hline B, water stress (7 days) & $0.49 \pm 0.02 b$ & $25.81 \pm 3.10 \mathrm{~b}$ & $15.72 \pm 1.85 \mathrm{~b}$ & $10.09 \pm 1.31 b$ & $11.33 \pm 1.93 \mathrm{~b}$ & $56.5 \pm 9.04 b$ & $3.45 \pm 0.59 \mathrm{~b}$ \\
\hline C, water stress (14 days) & $0.59 \pm 0.03 \mathrm{a}$ & $18.80 \pm 2.45 \mathrm{c}$ & $10.40 \pm 1.66 \mathrm{c}$ & $9.39 \pm 1.41 \mathrm{c}$ & $9.33 \pm 1.77 \mathrm{c}$ & $48.9 \pm 7.82 \mathrm{c}$ & $3.35 \pm 0.54 b$ \\
\hline
\end{tabular}

a Results are expressed as a mean value $\pm \mathrm{SD}(\mathrm{n}=3)$. The mean values in the table in the same column marked with the same letters do not differ statistically significantly at the level of significance $(\mathrm{P}<0.05)$

plants (Farahani et al., 2008); water stress decreased the aboveground plant yield (biological yield), plant height and length of internodes. In our study, in comparison to control (A), the mass of the aboveground plant part after 7 days (B) and 14 days of water stress was reduced by $35.68 \%$ and by $53.15 \%$, respectively. The average water loss from the leaves following the potted plants exposure to 7- and 14-days long water stress in comparison to control decreased by $30.13 \%$ and $53.78 \%$, respectively.

In their study, Farahani et al. (2008) revealed that the content of essential oil in C. sativum proved to be the highest under the longest water stress conditions, which is in agreement with our results. Water stress induced for 7- and 14-days prior to the harvest of lemon balm pot plants revealed increased content of essential oil in their leaves by $11.36 \%$ and $34.09 \%$, respectively, compared to control (A).

Comparison of results from our study with results of Farahani et al. (2009) revealed that in both studies water stress had similar effect on the content of lemon balm essential oil, though in our study the increase was much higher. Apart to the content, Farahani et al. (2009) also reported that the stress induced by water deficit significantly affected many other measured properties of lemon balm plants; the highest biological yield (6047 kg/ha), plant height $(61.51 \mathrm{~cm})$, leaf yield $(3447 \mathrm{~kg} / \mathrm{ha})$, stem yield $(2600 \mathrm{~kg} / \mathrm{ha})$, and internodes length $(5.17 \mathrm{~cm})$ were achieved under $80 \%$ water field capacity, which is comparable to the control pot treatment (A) in our study, while the highest content of the essential oil $(0.30 \%)$ was obtained at $20 \%$ water field capacity which is comparable to treatment C $(0.59 \%)$ in our study. Khalid (2006) described the influence of water stress on vegetative growth and essential oil contents of Ocimum basilicum L. and O. americanum L., where due to drought the dry masses of both plants were lower $(279 \mathrm{~g} /$ plant and $427 \mathrm{~g} /$ plant, respectively) than that in control (554 g/plant and $730 \mathrm{~g} /$ plant, respectively). The oil content in O. basilicum grown under the drought conditions was higher $(0.38 \%)$ than that in non-stress conditions $(0.33 \%)$, and similar was also observed in O. americanum ( $0.30 \%$ compared to $0.25 \%$ ), both implying the drought conditions cause a decrease in biomass yield, not necessarily accompanied by a decrease in the essential oil content. Therefore, it is often the case that in yields reduced due to a stress factor, the percentage of secondary metabolites in relation to the reduced biomass yield increases, which is in consistence to results obtained in our study (Table 1). Baher et al. (2002) investigated the influence of soil water stress on plant height, dry weight, and essential oil content in Satureja hortensis L, where the higher water stress decreased plant height $(43.33 \pm 2.90 \mathrm{~cm})$ and its dry mass $(34.23 \pm 3.00$ $\mathrm{g} /$ plant) compared to plants grown in non-stress conditions $(62.75 \pm 5.90 \mathrm{~cm}$ and $68.84 \pm 0.90 \mathrm{~g} /$ plant, respectively). Similar effects on the same parameters were also observed in our study. The accumulation of $S$. hortensis essential oil in the study of Baher et al. (2002) increased significantly under severe water stress at the flowering stage, and the contents varied from $1.75 \pm 0.02 \%$ in non-stress conditions to $2.30 \pm 0.01$ $\%$ in severe water stress treatment. This is consistent with our results, as the essential oil in leaves of $M$. officinalis varied from $0.44 \pm 0.02 \%$ in non-stress conditions to $0.59 \pm 0.03$ in extreme water stress conditions (Table 1). In their studies, Fatima et al. (1999) and Singh-Sangwan et al. (1994) found that water stress decreased plant height in various Cymbopogon sp. cultivars, Mirzaie et al. (2020) confirmed that in Cymbopogon citratus it caused an increase of essential oil yield and leaf anatomical structure alterations (glandular trichomes and stomatal size and density), while Simon et al. (1992) also reported for Ocimum basillicum significant increase of the essential oil content. The increase of essential oil content in plants grown under water stress conditions Nilsen and Orcutt (1996) attributed to stress-induced physiological disorder that happen during a photosynthetic phase, in which a decrease in $\mathrm{CO}_{2}$ absorption and high energy expenditure with less production of primary metabolites is required for further growth and development.

In the study of Mrlianová et al. (2001) yield of essential oil of lemon balm cultivated in 17 different regions of Europe ranged from $0.06 \%$ to $0.16 \%$. However, Moqbeli et al. (2011) implied that growing conditions including the type of soil used in production of lemon balm may have a great influence on content of essential oil, which in their study ranged from 0.20 to $0.68 \%$. Similar to our study, Sharafzadeh et al. (2011) studied production of lemon balm in greenhouse conditions, and reported increased content of its leaf essential oil (0.36 $\%)$. Bearing in mind that in our research lemon balm plants were grown in greenhouse conditions as a pot culture, we agree with the previous statements that production method, growing conditions and the type of soil may impact essential oil content. In addition, there is dependence of essential oil content and leaf position, the highest being observed in the physiologically most active, younger leaves; this was observed not only in case of lemon balm (Adzet et al., 1992) but also in lemongrass, another source of citral-rich essential oil (Singh et al., 1989). In study of Adzet et al. (1992), in the youngest leaves of lemon balm plants, the content of essential oil was more than $0.1 \%$ higher than in mature ones. Also, the highest content of the oil $(0.4 \%)$ was recorded in leaves harvested in September. Apart to this, the authors also proposed careful treatment of lemon balm leaves. In our study, the plants were young, it was the first harvest and the harvest was also late (September) and the leaves were collected with minimal manipulation, just prior to distillation procedure. 


\section{CONCLUSION}

This study showed that lemon balm grown as a pot culture in non-heated greenhouse conditions regularly watered during production period but exposed to water stress prior to harvest, showed the increased content of essential oil; the drought conditions caused a decrease in plants biomass which further resulted in higher leaf oil content. Therefore, if the potted lemon balm is grown for its essential oil, 7 to 14 days long abstinence from irrigation prior to harvest is advised as higher oil content could be expected (11.36 - 34.09\%). On the other hand, if the potted lemon balm is grown for its herb, water stress should be avoided as with regular drip irrigation the herb yield is comparable to that from the conventional field production.

\section{ACKNOWLEDGMENTS}

The authors appreciate the financial support of the Ministry of Education, Science and Technological Development of the Republic of Serbia (Grant: 451-03-9/2021-14/200003).

\section{REFERENCES}

Abuhamdah, S. and Chazot, P. L. (2008). Lemon balm and lavender herbal essential oils: Old and new ways to treat emotional disorders?, Current Anaesthesia \& Critical Care 19(4): 221-226.

Adzet, T., Ponz, R., Wolf, E. and Schulte, E. (1992). Content and composition of $M$. officinalis oil in relation to leaf position and harvest time, Planta Medica 58(06): 562-564.

Baher, Z. F., Mirza, M., Ghorbanli, M. and Bagher Rezaii, M. (2002). The influence of water stress on plant height, herbal and essential oil yield and composition in Satureja hortensis L., Flavour and Fragrance Journal 17(4): 275-277.

Basar, S. N. and Zaman, R. (2013). An overview of badranjboya (Melissa officinalis), 2: 3 .

Bazzazi, N., Khodambashi, M. and Mohammadi, S. H. (2013). The effect of drought stress on morphological characteristics and yield components of medicinal plant fenugreek, Isfahan University of Technology Journal of Crop Production and Processing 3(8): 11-23.

Burge, M. (1980). The use of lemon balm (Melissa officinalis) for attracting honeybee swarms, Bee World 61(2): 44-46.

Dastmalchi, K., Damien Dorman, H., Oinonen, P. P., Darwis, Y., Laakso, I. and Hiltunen, R. (2008). Chemical composition and in vitro antioxidative activity of a lemon balm (Melissa officinalis L.) extract, LWT - Food Science and Technology 41(3): 391-400.

Davies, F., Geneve, R., Wilson, S., Hartmann, H. and Kester, D. (2017). Hartmann \& Kester's Plant Propagation: Principles and Practices, $9^{\text {th }}$ edn, Pearson, NY, NY.

Farahani, A., Valadabadi, S. A., Daneshian, J. and Khalvati, M. A. (2009). Evaluation changing of EO of balm (Melissa officinalis L.) under water deficit stress conditions, Journal of Medicinal Plants Research 3(5): 329-333.

Farahani, H. A., Lebaschi, M. H. and Hamidi, A. (2008). Effects of arbuscular mycorrhizal fungi, phosphorus and water stress on quantity and quality characteristics of coriander, Advances in Natural and Applied Sciences 2(2): 55-60.

Fatima, S., Abad Farooqi, A. H., Ansari, S. R. and Sharma, S. (1999). Effect of water stress on growth and essential oil metabolism in Cymbopogon martinii (palmarosa) cultivars, Journal of Essential Oil Research 11(4): 491-496.

Khalid, K. A. (2006). Influence of water stress on growth, essential oil, and chemical composition of herbs (Ocimum sp.), International Agrophysics 20: 289-296.

Mirzaie, M., Ladanmoghadam, A. R., Hakimi, L. and Danaee, E. (2020). Water stress modifies essential oil yield and composition, glandular trichomes and stomatal features of lemongrass (Cymbopogon citratus) inoculated with arbuscular mycorrhizal fungi, Journal of Agricultural Science and Technology 22(6): 1575-1585.

Moqbeli, E., Fathollahi, S., Olfati, J. A., Peyvast, G. A., Y., H. and D., B. (2011). Investigation of soil condition on yieldand essential oil in lemon balm, Journal of Horticulture, Biology and Environment 2(1): 87-93.
Moradkhani, H., Sargsyan, E., Bibak, H., Naseri, B., Sadat-Hosseini, M., Fayazi-Barjin, A. and Meftahizade, H. (2010). Melissa officinalis L., a valuable medicine plant: a review, Journal of Medicinal Plants Research 25(4): 2753-2759.

Mrlianová, M., Tekel'ová, D., Felklová, M., Tóth, J., Musil, P. and Grancai, D. (2001). [Comparison of the quality of Melissa officinalis L. cultivar Citra with mellissas of European origin], Ceska a Slovenska Farmacie 50(6): 299-302.

Nilsen, E. T. and Orcutt, D. M. (1996). The physiology of plants under stress,, Vol. 1 of Abiotic factors, $2^{\text {nd }}$ edn, John Wiley \& Sons, New York.

Németh-Zámbori, v., Szabó, K., Pluhár, Z., Radácsi, P. and Inotai, K. (2016). Changes in biomass and essential oil profile of four Lamiaceae species due to different soil water levels, Journal of Essential Oil Research 28(5): 391-399.

Pereira, R. P., Boligon, A. A., Appel, A. S., Fachinetto, R., Ceron, C. S., Tanus-Santos, J. E., Athayde, M. L. and Rocha, J. B. T. (2014). Chemical composition, antioxidant and anticholinesterase activity of Melissa officinalis, Industrial Crops and Products 53: 34-45.

Ph. Jug. IV (1984). Yugoslav Pharmacopoeia IV, Federal Institute of Public Health, Belgrade, Serbia.

Ramakrishna, A. and Ravishankar, G. (2011). Influence of abiotic stress signals on secondary metabolites in plants, Plant Signal 6(11): 1720-1731.

Schultze, W., A., Z., S., H., H., K. K. and C., C. F. (1992). Volatiles in flowers of balm (Melissa officinalis I.)., in R. M. Harley and R. M. Reynolds (eds), Advances in Labiate science, $9^{\text {th }}$ edn, Royal Botanic Gardens, Kew, pp. 357-366.

Sharafzadeh, S., Khosh-Khui, M. and Javidnia, K. (2011). Aroma profile of leaf and stem of lemon balm (Melissa officinalis L.) grown under greenhouse conditions, Advances in Environmental Biology pp. 547551.

Simon, J. E., Reiss-Bubenheim, D., Joly, R. J. and Charles, D. J. (1992) Water stress-induced alterations in essential oil content and composition of sweet basil, Journal of Essential Oil Research 4(1): 71-75.

Singh, N., Luthra, R. and Sangwan, R. (1989). Effect of leaf position and age on the essential oil quantity and quality in lemongrass (Cymbopogon flexuosus) ${ }^{1}$, Planta Medica 55(03): 254-256.

Singh-Sangwan, N., Abad Farooqi, A. H. and Singh Sangwan, R. (1994). Effect of drought stress on growth and essential oil metabolism in lemongrasses, New Phytologist 128(1): 173-179.

Świąer, K., Wijaya, C. H. and Startek, K. (2019). The therapeutic properties of lemon balm (Melissa officinalis L.): Reviewing novel findings and medical indications, Journal of Applied Botany and Food Quality 92: 327-335. 